\title{
Parasitoid Lalat Pengorok Daun pada Pertanaman Kentang dan Tumbuhan Liar di Wilayah Pangalengan
}

\author{
PURNOMO, A. RAUF, S. SOSROMARSONO, DAN T, SANTOSO \\ Jurusan Protcksi Tanaman Fakultas Pertanian Unila \\ Kampus Gedungmeneng Bandar Lampung \\ (diterma Oktober 2004, disetujui .Ipril 2005)
}

\begin{abstract}
Parasitoids of Leafminer Fly on Potato Fields and Non-Crop Vegetation in Pangalengan Arca. The damage leaves of potato and non-crop vegetation caused by leafminer fly Linomyza baidobrensis (Blanchard) (Diptera: Agromzidae) were collected during August-October 2000 in Pangalengan area to evaluate the role of non-crop vegetation on the abundance of leafminer fly and its parasitoids. The leaves were placed into the bowls. The fly and parasitoids that emerged from the leaves were noted afterwards. The result of this survey showed that six families of plant were the host of $L$ - buidobrensis on non-crop vegetation around the potato plantation. Those families are, Amaranthaceae, Asteracenc, Chenopodiaceac, Convolvulaceae, Malvaceae, and Solanaceae. The most abundant of non-crop vegetation found in the field was galingrang (Gallusoga pariflora). The parasitoids that emerged from the non-crop vegetation were Hemiptarsenss varionnis (Girault) (Hymenoptera: Eulophidae) and Opiss sp. (Hymenoptera: Braconidae). The proportion of emerged fly were $68.5 \%$ from non-crop vegetation and $58.8 \%$ from porato, while those of parasitoids were $31.5^{\circ} \%$ from non-crop vegetation and $41.2^{\mathrm{n}} \%$ from potato. Generally, non-crop vegetation in Pangalengan more potent as reservoar of pest than parasitoids.
\end{abstract}

KEY WORDS: Potato, non-crop, vegetation, Linomyza huidobrensis, Heniptarienses tariornis, Opius sp.

\section{PENDAHULUAN}

Lalat pengorok daun kentang, Linomya buidobrensis (Blanchard) (Diptera: Agromyzidae), adalah hama yang saat ini paling banyak menimbulkan kerusakan pada tanaman kentang di Indonesia. Sejak ditemukan pertama kali pada tahun 1994 di Cisarua (Rauf, 1995), hama ini telah menyebar ke berbagai sentra produksi sayuran dataran tinggi di Jawa, Sumatera, dan Sulawesi.

Lalat $I$, hidobrensis adalah hama yang bersifat polifag (Parrella, 1987).
Selain pada kentang, di Indonesia hama ini juga banyak menimbulkan kerusakan berat pada sayuran seperti horinso, tomat, seledri, dan ketimun (Rauf, 1995), dan berbagai tumbuhan bunga yang diusahakan di rumah plastik (Rauf et al., 1999), serta beragam tumbuhan liar (Setiawati et al., 1997). Secara umum tumbuhan inang $L_{-}$buidobrensis meli-puti anggota famili Solanaceac, Brassica-ceae, Asteraceae, Fabaceac, Amarantha-ccac, Liliaceae, Chenopodiaceae, Caryophylaceae, Lamiaceae, dan Capparidaceac (Rauf et al., 1999; 2000). 
Peranan tumbuhan liar di agroekosistem dalam hubungan dengan populasi lalat pengorok daun telah dikemukakan oleh beberapa peneliti. Wolfenbarger (1961) memperkirakan bahwa tumbuhan liar kurang penting dalam menunjang peningkatan populasi lalat pengorok daun mencapai tingkat epidemi. Steigmaier (1966) menyatakan bahwa tumbuhan liar berperan sebagai reservoar lalat pengorok daun, terutama pada saat infestasi awal (Genung and Janes, 1975). Sementara itu Schuster $t$ al. (1991) memperkirakan bahwa tumbuhan liar berperan penting sebagai reservoar parasitoid lalat pengorok daun.

Everaats (1981) melaporkan terdapat 35 spesies tumbuhan liar yang dijumpai di dacrah sayuran dataran tinggi di Jawa. Pengamatan lapangan selama ini menunjukkan bahwa beberapa jenis tumbuhan liar yang tumbuh pada dan di sekitar pertanaman kentang diketahui merupakan inang lalat pengorok daun $L$ buidobrensis, dan pada giliran betikut-nya larva lalat ini menjadi inang bagi parasitoid. Belum diketahui secara rinci dan kuantitatif kelimpahan relatif antara lalat pengorok daun dan parasitoidnya pada tumbuhan liar. Penelitian ini bertujuan untuk menginventarisasi tumbuhan liar yang tumbuh di arcal pertanaman kentang di Pangalengan, dan untuk mengkaji potensinya sebagai reserroar lalat pengorok daun dan parasitoidnya.

\section{BAHAN DAN METODE}

Penelician dilaksanakan pada agroekosistem kentang di wilayah Pangaleng- an Bandung, dan berlangsung sejak Agustus hingga Oktober 2000. Contoh daun kentang bergejala korokan diambil setiap minggu sebanyak lima kali dari pertanaman kentang yang tidak diaplikasi insektisida. Pada saat yang hampir bersamaan dilakukan juga pengambilan contoh daun dari tumbuhan liar yang terserang $L$ buidobrensis. Daun yang diambil contohnya berasal dari tumbuhan liar yang terdapat pada petakan kentang, petakan sayuran lain, lahan bekas tanaman kentang, dan di sekitar perkebunan teh yang berdekatan dengan pertanaman sayuran. Kunjungan lapangan untuk mengambil contoh daun tumbuhan liar dilakukan sebanyak lima kali. Pada tiap kunjungan, kelimpahan tumbuhan liar dicatat secara kualitatif dan dikategorikan sebagai: tidak ditemukan $(-)$, sedikit $(+)$, agak banyak $(++)$, dan banyak $(+++)$.

Banyaknya daun contoh yang diambil pada setiap kunjungan lapang berjumlah minimal 25 helai untuk tiap jenis tumbuhan. Di laboratorium tiap helai daun contoh dimasukkan ke dalam cawan plastik (diameter $6 \mathrm{~cm}$, tinggi $5 \mathrm{~cm}$ ) yang bertutup rapat. Sebelumnya, selembar kertas tissu diletakkan pada bagian dalam alas cawan dengan maksud untuk menyerap air yang menguap dari daun. Dengan cara ini diharapkan daun tidak cepat membusuk. Banyaknya imago lalat yang muncul, pupa yang gagal, dan jenis serta banyaknya imago parasitoid yang muncul dicatat.

Identifikasi tumbuhan liar dilakukan oleh Herbarium Bogoriense-Bogor, 
sedangkan parasitoid diidentifikasi berdasarkan koleksi acuan yang ada di Jurusan Hama dan Penyakit Tumbuhan, Fakultas Pertanian-IPB.

\section{HASIL DAN PEMBAHASAN}

\section{Lalat Pengorok Daun dan Parasitoid pada Tanaman Kentang}

Sekitar 59\% dari imago serangga yang muncul dari daun kentang yang bergejala korokan adalah lalat pengorok L. buidobrenis, dan sisanya adalah imago parasitoid Hemiptarients varicornis (Girault) (Hymenoptera: Eulophidae) dan Opins sp. (Hymenop-tera: Braconidae) (Tabel 1). Jenis pa-rasitoid yang disebut pertama adalah ektoparasitoid larva (Hidrayani et al., 2002), sedangkan yang kedua adalah endoparasitoid larva-pupa (Rustam et al., 2002). Keberadaan $H$. varicornis sebagai parasitoid larva $L$ buidobrensis telah dilaporkan sejak awal kedatangan hama ini di Indonesia. Supartha (1998) yang meneliti dinamika populasi L. buidobrensis pada pertanaman kentang di Lembang pada tahun 1997 mendapatkan hanya $H$. varicomis yang berasosiasi dengan hama ini, dengan rataan tingkat parasitisasi sckitar $40 \%$. Survei intensif yang dilaku- kan pada berbagai tumbuhan termasuk gulma dan tanaman hias oleh Rauf el al. (2000) juga mendapatkan $H$. varicormis sebagai parasitoid yang paling dominan. Keberadaan Opitts sp. scbagai parasitoid $L$ htidobrensis baru dilaporkan pada hasil survei yang dilakukan pada tahun 1999/2000 (Rauf and Shepard, 2001). Namun, tulisan tadi tidak mengungkapkan secara kuantitatif tingkat kelimpahannya. Pada penelitian yang dilakukan di Pangalengan (Tabel 1) tampak bahwa parasitoid $H$. varicornis lebih banyak muncul dari daun contoh yang dikumpulkan pada saat tanaman kentang berumur 6 dan 7 minggu setelah tanam (mst), dan setelah itu proporsinya menurun. Sebaliknya, parasitoid Opins sp. lebih banyak muncul dari daun contoh yang dikumpulkan pada 9 dan 10 mst.

Kehadiran Opizs sp. sebagai parasitoid L bsidobrensis pada tanaman kentang diharapkan dapat membantu unjuk kerja parasitoid H. varicormis dalam menekan populasi dan serangan lalat pengorok daun. Berdasarkan pemantauan lapangan dan ditunjang oleh hasil wawancara dengan petani terdapat indikasi penurunan intensitas serangan lalat pengorok daun pada pertanaman kentang dalam dua tahun belakangan ini

Tabel 1. Proporsi imago yang muncul dari daun kentang yang terserang lalat pengorok daun.

\begin{tabular}{lccccc}
\hline \hline \multirow{2}{*}{ Umur tanaman (mst) } & \multirow{2}{*}{$\begin{array}{c}\text { Banyaknya imago } \\
\text { serangga muncul }\end{array}$} & \multicolumn{4}{c}{ Proporsi (\%) } \\
\cline { 3 - 6 } & & L. huidobrensis & H. varicornis & Opius sp. & Total parasitoid \\
\hline 6 & 103 & 67,0 & 31,1 & 1,9 & 33,0 \\
7 & 84 & 52,4 & 28,6 & 19,0 & 47,6 \\
8 & 108 & 54,6 & 22,2 & 23,2 & 45,4 \\
9 & 102 & 52,9 & 13,8 & 33,3 & 47,1 \\
10 & 93 & 66,7 & 0,0 & 33,3 & 33,3 \\
Keseluruhan & 490 & 58,8 & 19,2 & 22,0 & 41,2 \\
\hline
\end{tabular}


relatif terhadap saat awal kedatangan hama ini pada tahun 1995/1996. Tidak diketahui dengan pasti penyebab utama menurunnya serangan $L$ buidobrensis, tapi mungkin ada kaitannya dengan bertambahnya jenis parasitoid yang berasosiasi dengan lalat pengorok daun ini.

\section{Lalat Pengorok Daun dan Para-sitoid Pada Tumbuhan Liar}

Selama survei berlangsung dijumpai 11 spesies tumbuhan liar, mewakili enam famili, yang memperlihatkan gejala korokan $L$ bsidobnensis (Tabel 2). Jenis yang sering ditemukan dengan status kelimpahan yang tinggi $(+++)$ adalah galinggang, jambrong, dan babauan. Tumbuhan liar lainnya yang dilaporkan (Rauf el al,, 2000, Setiawati et al., 1997) dapat menjadi inang lalat pengorok daun kentang adalah sawi tanah,

Nasturtium indicum (L.) Hassk. (Brassicaceac); jonge, Emilia sonchifolia (L.) DC, lampenas, Lactuca indica L., babadotan, Ageralum conyroides L, babadotan lalaki, Synedrella nodiffora (L.) Gaertn. (Asteraceae); cecendet, Pbysalis angulata L. (Solanaceae); seng-gang, Amaranthus spinosus L. (Amaran-thaceae); gandola, Basella alba L. (Basellaceae).

Berdasarkan proporsi banyaknya imago lalat pengorok daun dan parasitoid yang muncul dari daun contoh (Tabel 3), secara umum tumbuhan liar dapat digolongkan ke dalam tiga kelompok: 1) tumbuhan liar yang menghasilkan imago lalat pengorok daun lebih banyak daripada imago parasitoid, 2) tumbuhan liar yang menghasilkan imago lalat pengorok dan parasitoid dengan proporsi yang hampir sama, dan 3) tumbuhan liar yang menghasilkan imago parasitoid lebih banyak daripada imago lalat pengorok daun.

Kelompok pertama meliputi bayam merah, babauan, pungpurutan, jambrong, dan leunca. Dari tumbuhan liar ini, imago serangga yang muncul umumnya adalah lalat pengorok daun dengan proporsi berkisar antara $68 \%$ (jambrong, leunca) hingga lebih dari $80 \%$ (bayam merah, Babauan, pungpurutan) (Iabel 3). Yang tergolong kelompok kedua adalah bayam hijau dan galinggang, dengan proporsi lalat pengorok daun 48-58\%. Kelompok ketiga adalah boboledan. Dari tumbuhan ini hanya imago parasitoid yang muncul. Proporsi jenis parasitoid yang muncul bervariasi antar tumbuhan liar. Dart bayam dan babauan, parasitoid yang lebih banyak muncul adalah $H$. variornis; sedangkan parasitoid Opius sp. lebih banyak muncul dari galinggang, boboledan, pungpurutan, dan leunca (Tabel 3).

Selain ketiga kelompok seperti disebutkan di atas, terdapat tumbuhan liar (Telur kodok dan kembang dayang) yang menghasilkan korokan yang abortif. Dari kedua tumbuhan tadi, tidak satu pun muncul imago L buidobrenis maupun parasitoid. Pengamatan menunjukkan korokan berukuran sempit dan tidak berkembang seperti pada daun tumbuhan lainnya. Pembedahan menunjukkan tidak terdapat larva atau pupa dalam korokan. Kegagalan proses pengorokan ini diduga karena terjadi kematian pada 
larva instar awal. Fenomena korokan abortif dilaporkan pula terjadi di Mauritius seperti pada Solanum nigrum L. dan Sethium edule (Jacq.) Swartz yang diserang oleh $L$ irifoliil, dan diduga terkait dengan sifat antibiosis yang di-miliki oleh tumbuhan (Fagoonee and Toory, 1984).

\section{Tumbuhan Liar: Reservoar Lalat Pengorok Daun atau Parasitoid?}

Hasil penelitian yang dilakukan menunjukkan bahwa tumbuhan liar me- rupakan habitat bagi lalat pengorok daun maupun parasitoidnya. Tumbuhan liar yang paling sering dijumpai adalah galinggang, babauan, dan jambrong. Keberadaan ketiga jenis tumbuhan ini di sekitar pertanaman kentang dapat mempengaruhi kelimpahan lalat pengorok daun dan parasitoid pada tanaman budidaya. Genung (1981) melaporkan bahwa gulma yang tumbuh di sckitar hamparan seledri di Florida mempengaruhi kelimpahan lalat pengorok daun dan

Tabel 2. Tumbuhan liar yang menjadi inang $L$. huidobrensis di wilayah Pangalengan selama Agustus-Oktober 2000 .

\begin{tabular}{|c|c|c|c|c|c|c|}
\hline \multirow{2}{*}{ Famili dan spesies } & \multirow{2}{*}{ Nama daerah } & \multicolumn{5}{|c|}{ Status kelimpahan pada saat survei } \\
\hline & & $21-08-00$ & $27-08-00$ & $12 \cdot 09 \cdot 00$ & $27-09-00$ & $16-10-00$ \\
\hline \multicolumn{7}{|l|}{ Amaranthaceae } \\
\hline Amaranthus dubius Mart. & Bayam hijau & ++ & ++ & + & ++ & - \\
\hline $\begin{array}{l}\text { Amaranthus tricolor } \mathrm{L} \text {. } \\
\text { var. mangostanus }\end{array}$ & Bayam merah & + & + & - & + & $\cdot$ \\
\hline \multicolumn{7}{|l|}{ Asteraceae } \\
\hline Galinsoga parvifiora Cav. & Galinggang & +++ & +++ & - & +++ & +++ \\
\hline Erechites hieracifolia (L.) Raf. & Jambrong & ++ & +++ & - & +++ & +++ \\
\hline $\begin{array}{l}\text { Erechites valerianaefolia DC } \\
\text { Chenopodiaceae }\end{array}$ & Sintrong & + & + & - & - & - \\
\hline $\begin{array}{l}\text { Chenopodium ambrosiodes L. } \\
\text { Convolvulaceae }\end{array}$ & Babauan & +++ & +++ & ++ & - & +++ \\
\hline $\begin{array}{l}\text { Lepistemon binectariferum Kuntze } \\
\text { Malvaceae }\end{array}$ & Boboledan & - & - & ++ & - & ++ \\
\hline $\begin{array}{l}\text { Usena lobata L. } \\
\text { Solanaceae }\end{array}$ & Pungpurutan & - & - & + & + & - \\
\hline Nicandra physalodes (L.) Gaertn. & Telur kodok & - & + & - & - & +++ \\
\hline Solanum americanum Miller & Leunca & $\cdot$ & ++ & ++ & - & ++ \\
\hline Cestrum pallidissimum Francey & Kembang dayang & ++ & - & - & - & + \\
\hline
\end{tabular}

Keterangan $:=($ tidak dijumpai $),+=($ sedikit $),++=($ agak banyak $),+++=($ banyak $)$.

Tabel 3. Proporsi imago L, huidobrensis dan parasitoid yang muncul dari daun tumbuhan liar.

\begin{tabular}{|c|c|c|c|c|c|c|}
\hline \multirow[b]{2}{*}{ Tumbuhan liar } & \multirow{2}{*}{$\begin{array}{c}\text { Banyaknya } \\
\text { daun contoh } \\
\text { (helai) }\end{array}$} & \multirow{2}{*}{$\begin{array}{c}\text { Banyaknya } \\
\text { imago muncul } \\
\text { (ekor) }\end{array}$} & \multicolumn{4}{|c|}{ Proporsi (\%) } \\
\hline & & & L. huidobrensis & H. varicomis & Opius sp. & $\begin{array}{c}\text { Totai } \\
\text { parasitoid }\end{array}$ \\
\hline Bayam hijau & 99 & 105 & 58,1 & 28,6 & 13,3 & 41,9 \\
\hline Bayam merah & 75 & 37 & 94,6 & 5,4 & 0,0 & 5,4 \\
\hline Galinggang & 139 & 185 & 48.6 & 1.4 & 33,0 & 51,4 \\
\hline Telur kodok & 48 & 0 & 0 & 0 & 0 & 0 \\
\hline Sintrong & 51 & 30 & 0,0 & 0,0 & 0,0 & 0,0 \\
\hline Babauan & 126 & 187 & 85,0 & 13,9 & 1,1 & 15,0 \\
\hline Boboledan & 45 & 18 & 0.0 & 0,0 & 18 & 100,0 \\
\hline Pungpurutan & 62 & 61 & 83.6 & 4,9 & 11.5 & 16.4 \\
\hline Jambrong & 114 & 138 & 68,8 & 11,6 & 19,6 & 31,2 \\
\hline Leunca & 74 & 74 & 68.9 & 6.8 & 24.3 & 31.1 \\
\hline Kembang dayang & 39 & 0 & 0 & 0 & 0 & 0 \\
\hline Keseluruhan: & & 835 & 68,5 & 13,9 & 17,6 & 31.5 \\
\hline
\end{tabular}


parasitoid pada tanaman seledri tadi. Pada penelitian di Pangalengan ditunjukkan bahwa secara keseluruhan imago serangga yang muncul dari tumbuhan liar terdiri dari $68,5 \%$ lalat $L$ buidobrensis dan $31,5 \%$ parasitoid (Tabel 3). Hal ini mengisyaratkan bahwa secara umum tumbuhan liar lebih berpotensi sebagai reservoar hama daripada musuh alami. Untuk menetapkan secara lebih pasti proporsi lalat pengorok daun dan parasitoidnya pada tumbuhan liar, survei kiranya perlu dilakukan dalam jangka waktu yang lebih lama dan areal yang lebih luas. Selain itu, laju invasi lalat pengorok daun dan parasitoid dari tumbuhan liar ke tanaman kentang perlu diketahui. Seluruh informasi tadi diharapkan dapat menambah pemahaman kita tentang pengaruh rumbuhan liar terhadap populasi lalat pengorok daun dan parasitoid pada tanaman yang dibudidayakan.

Beberapa spesies pengorok daun lain yang menyerang gulma dilaporkan memiliki jenis parasitoid yang sama dengan Lirion) ra. Sebagai contoh Phaedrotoma scabriventris Nixon (Hymenoptera: Braconidae) adalah parasitoid yang paling penting pada $L$ buidobrensis di Argentina (Valladares and Salvo, 1999). Parasitoid ini juga memarasit lalat pengorok daun Haplopeodes luivora Valldares yang hanya menyerang tumbuhan liar Lyizum cestroides Schlecht (Valladares, 1998). Dengan demikian, tumbuhan liar tadi menyediakan inang alternatif bagi parasitoid. Di Florida, Parkman et al. (1989) melaporkan $L_{-}$commelinae (Frost) ha-nya menyerang gulma Cammelina diffura Burm yang memiliki kesamaan parasitoid dengan L trifolii. Dalam hubungan ini, Van der Linden (1992) mengusulkan sistem pembiakan massal terbuka untuk pengendalian hayati Lirionyza spp., dengan memanfaatkan tumbuhan liar sebagai reservoar bagi inang alternatif untuk parasitoid.

Tidak diketahui dengan pasti inang alternatif bukan-hama dari $H$. varicornis. dan Opizs sp. yang ada di Indonesia. Namun karena parasitoid pengorok daun umumnya bersifat generalis (Murphy and LaSalle, 1999), diperkirakan bahwa parasitoid H. rariornis dan Opius sp. juga dapat memanfaatkan spesies pengorok daun lainnya yang bukan hama. Jenis pengorok daun tadi di antaranya adalah Agromyza panici De Meijere pada Panicum palmifolium, Calycomyøa lantanae pada Lantana spp., dan Pserdonapomyza asiatica pada Cynodon datylon (Sasakawa and Pong, 1990). Perlu kiranya dilakukan pene-litian yang dapat mengungkapkan jenis-jenis pengorok daun bukan-hama pada tumbuhan liar dan komunitas parasitoid yang berasosiasi dengannya. Melalui pemahaman ini diharapkan pengelolaan musuh alami L. huidobrensis pada agroekosistem kentang dan sayuran lainnya dapat didasarkan pada pendekatan jala-makanan parasitoid seperti yang diusulkan oleh Memmot and Godfry (1993). 


\section{KESIMPULAN}

Berdasarkan status kelimpahan dari tiap jenis tumbuhan liar dan proporsi imago serangga yang muncul, secara umum tampaknya tumbuhan liar yang ada pada dan di sekitar pertanaman kentang di Pangalengan lebih berpotensi sebagai reservoar lalat pengorok daun daripada sebagai reservoar parasitoidnya. Penelitian lanjutan perlu diarahkan pada pengungkapan jenis pengorok daun bukan-hama pada tumbuhan liar dan komposisi parasitoidnya, serta hubungannya dengan parasitoid pengorok daun pada tanaman budiclaya.

\section{DAFTAR PUSTAKA}

Exerats. 1981. Weeds of Vegetables in The lighlands of lava. lakarta: Horticultural Research Institute. 121 p.

Figoonec, I. and V. Toory. 1984. Contribution to The Study of The Biology and Ecology of the Jeafminer lirionzed trifolit and Its Control by Necm. Insect Sci Appl 5(1):2330.

Genung. W.G. 1981. Weed Hosts of Liriamya and Parasite Incidence in The Celer t tgroEcosysiem at Belle Glade, Florida. Dalam: Schuster, D.J. (F.dr.). Proceedings, IFAS. industry conference on the biology and control of Liromza leafminers, November 34, 1981. I ake Buena Vista, Fia. Institute of lood and Agricultural Sciences, Universing of Florida, Gainesville. p. 61-69 , and M.J. Janes. 1975. Host Range, wild Host Significance, and Infield Spread of linimyad trifolit and Population Buildup and leffects of lts Parasites in Retarion to Fill and Winter Celery (Diptera: - Igromyzidac). Univ. Fa Institute of Food and Agricultural Sciences, Agric. Res. F.du. Cent. Rep. EV-1975(5).

Hidarani, A. Rauf, S. Sosromarsono, dan U. Kartosuwondo. 2002. Biockologi Hemiptarsents mationis (Girault) (Iymenoptera: Eulopludac), Parasioid
Linomya baidobnsis (Blanchard) (Diptera: Agromyzidae). Makalah disampaikan pada seminar Program Pascasarjana IPB, Bogor. 7 Oktober 2002. $16 \mathrm{p}$.

Nemmot, J. dan H.C.I. Ciodfry. 1993. Parasitoid webs. In Lasille, I. and Gatuld 1.D. (Eds). Hymenopiera and liso diversity. C.MB Wallingford, LK, p: $21^{-}$ 234

Murphy, S.T and J. LaSalle, 1999, Balancing Biological Control Strategics in The IlPM of New World Invasive Linionjza leafininer. in Vegetable Crops. Bio-control News and Information. 20(3):91-104.

Parkman, P., J... Dusky, and V.1I Waddall. 1989. Leafminer and J teatminer Patrisitoid Incidence on Selected Weeds in south Flortda. 14a. Entomol 72(3):559-561.

Parrella, M.P. 1987. Biology of I iminmza. Innu Rev. Fintomol. 32:201-21-4.

1995. Limonyar. Ilama Pendatang Baru di Indonesia. Bull. Hama dan Penyakit Tumbuhat 8(1): $+6-48$. and B.M. Shepard. 1999. Isatminers in Vegetables in Indonesia: Surveys of bost crops, species composition, parasituids and control practices, Dalame Lam G.S. Soctikno, S.S., and toke, W.II. (Edo.). Proceedings of a workshop on leafminers of vegerables in Southeast Ista, Tatnah Rata, Nalavsia: 2-5 Februari 1999. (...BB Intemational South Lisst Asla Regional Centre. p. 25.35.

, B.M. Shepard, and MNW. Johnson. $200 \mathrm{n}$. leafminers in vegetables, ornamental plants and weeds in Indonesin: surveys of host crops, species compositio and parasitoids. Intern I. Pest Matuage $46(4): 257-266$.

and B.M. Shepard. 200t. Current status on the biology, ecology and management of liriomyza spp. in Indonessa wath emplasis on $I_{\text {. }}$ botidobremit. Paper presented at semmar on maistre arthropod pests of regetables and economic food crops, Kuala lumpur Mfalaysta, 13-14 March 2001. $8 \mathrm{p}$.

Rustam, R, .1. Rauf, dan N. Marçana. 2(4012. Biologi Optus sp. (Hymenoprera: Braconidac), parasitoid lalat pengorok daun kentang. Makalah disampaikan padat seminar Program Pascasariana IPl3, Bogor. 5 . Igustus 2(102. $14 \mathrm{p}$. 
Sasakawa, $K$ and T.Y. Pong. 1990. Agromyzidace (Dipteria) of Malaysia (Part 2). Jpn. I. Entomol, 58(4):871-878.

Schuster, D.J., J.P. Gilreath, R.A. Wharton, P.R. and Seymour. 1991. Agromyzidac (Diptera) leafminer and their parasitoids in weeds assosiated with tomato in Florida. Environ. Entomol. 20(2);720-723.

Sctiawat, W. ES Rustamana, dan Laksanatwati. 1907. Inventarisasi pencaran hama I Jrianyes sp. (Diptera: Agromyzidac) dan musuh alaminy̧a pada tanaman kentang. Balat Penclitian Tanaman Sayuran l.embang. $16 \mathrm{p}$.

Sregmaicr Jr, C.E. 1966. Host plants and parasites of Liriomya /rifolit in Forida (Diptera: Agromyzidae). Fla. Entomol. 49:79.81.

Supartha, 1W: 1998. Bionomi linomza hididobrensis (Blanchitrd) (Dipterat
Agromyzidae) pada tanaman kentang [disertasi], Bogor: Institut l'ertanian Bogor. Program Pascasarjata.

Valladares, G. 1998. Three new species of Haplopeodes Stcyskai (Dipt.: Agromỹzidac) from Argentina. Entomol. Mont. Mag. 134:31-38.

and Salvo . 1. 1999. Insect plant food welss could provide new clucs for pest management. Finviron. lintemes]. $28(4)-539-544$.

Van der Linden A. 1992. Plytamiga candinam Hering, an altemative host for the development of an open rearing system for parasitoids of I iniany a species. Proc. Lxp. Appl. Entomol. 3:31-39.

Wolfenbarger, D.O. 1961. Leafmining insects, especially the serpentine misers on vegetable crop plants and theit control Proc. Fla. State Hortic. Soc. 74:131-13.3. 